\title{
DO NETIZEN AO NEOCONSUMIDOR: CIDADANIA SEM LIMITES NA INTERNET
}

\section{FROM NETIZEN TO NEOCONSUMER: CITIZENSHIP WITHOUT LIMITS ON THE INTERNET}

\author{
Arquimedes Pessoni* \\ Robson Luiz Gisoldi ${ }^{* *}$
}

\section{RESUMO}

Este artigo busca conceituar e refletir a participação da sociedade na internet, no que tange a forte participação do cidadão nas redes sociais virtuais, seja para cobrar governos ou empresas. Com a chegada de novas plataformas tecnológicas, a sociedade teve sua voz amplificada, formando um verdadeiro "coro" de elementos da cidadania que formam opinião, constroem ou derrubam reputações e cravam um novo contexto na relação entre organizações e clientes, munícipes e grupos sociais.

Palavras-chave: Inovação. Cidadania. Redes Sociais. Participação. Sociedade.

\begin{abstract}
This article aims to conceptualize and reflect about society's participation on the internet, in particular the strong citizen participation in virtual social networks that demand actions from governments or companies. With the arrival of new technology platforms, society had expanded its voice, forming a true "chorus" of citizens that form opinion, build or destroy reputations and create a new context in the relationship between organizations and customers, citizens and social groups.
\end{abstract}

Keywords: Innovation . Citizenship. Social networks . Participation.Society.

\footnotetext{
"Professor no curso de pós-graduação em Comunicação e na graduação de Jornalismo da Universidade Municipal de São Caetano do Sul, USCS, Brasil. Doutor em Comunicação Social pela Universidade Metodista de São Paulo (UMESP)

${ }^{*}$ Professor no Centro Universitário Anhanguera - Mestre em Comunicação pela Universidade Municipal de São Caetano do Sul, USCS
} 


\section{Introdução}

Com a informação rápida pulsando a cada segundo na tela dos computadores ou até mesmo em um simples celular, a cobrança por respeito a prazos estabelecidos, qualidade do produto e bom atendimento, está formando coro na internet. Os cidadãos, seja na forma de sua participação cidadã ou como consumidores, têm feito o uso das ferramentas disponíveis para comparar empresas, produtos e questioná-las se necessário. Esse novo processo de comunicação, que já existia no passado e agora é amplificado pela internet, torna a cobrança por serviços públicos de qualidade, pela falta de manutenção ou por obras inacabadas, uma grande propulsora de um estrago da imagem institucional de qualquer instituição.

Não há como negar que o advento das novas mídias sociais tem influenciado cada vez mais o comportamento comum. Não que antes não havia reclamações quanto aos produtos e serviços disponíveis, seja no popular 'boca a boca' ou na imprensa, mas é perceptível que esse fenômeno foi ampliado com o advento da internet, ainda mais com as diversas possibilidades de compartilhamento que as mídias sociais colocam à disposição da sociedade. Para lidar com este novo fenômeno, diversas organizações estão estruturando seus departamentos de comunicação, SAC (Serviço de Atendimento ao Consumidor), Fale Conosco e ouvidorias, dentre outros canais, para mapear as mídias que podem gerar reclamação pública de seus serviços, minimizando os impactos em sua imagem institucional. Vários conceitos surgiram para explicar essa mudança na participação social. Na visão de Mounier (2006), esses sujeitos que veem na internet uma ferramenta da liberdade de expressão e acreditam que elas "não são somente tecnologias, mas também meios de expressão" dão-se o nome de "netizens".

Em uma linha semelhante, a figura a seguir exemplifica o conceito de consumidor social, apontando um perfil adepto da Internet na hora de comprar produtos e serviços. É necessário destacar apenas que seu comportamento apresenta algumas peculiaridades: prefere declarar sua insatisfação com o serviço prestado via rede social, preterindo os canais de atendimento das organizações, pois considera, além da facilidade, uma forma de ter retorno mais rápido e dividir sua "indignação" com outros "internautas".
Figura 01 - Complexidade do novo consumidor social

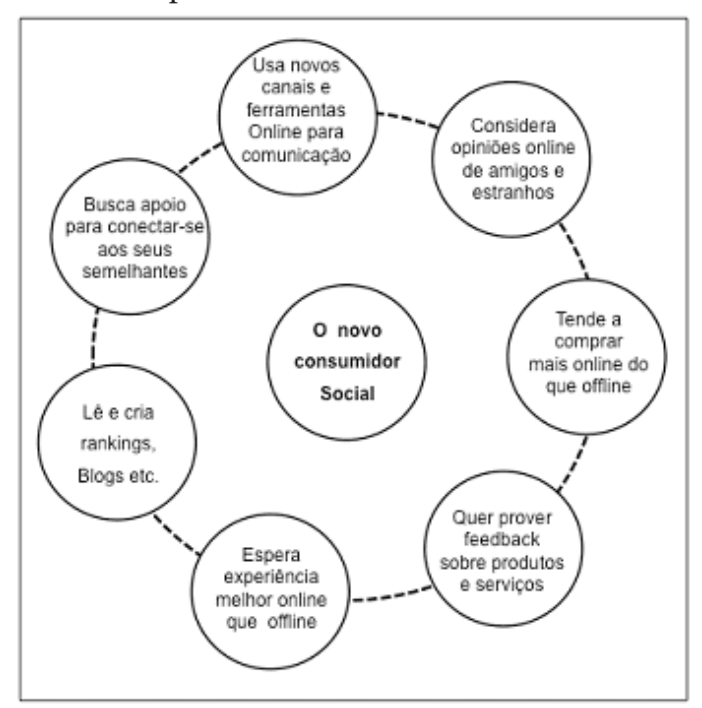

Fonte: Deloitte- Pesquisa As mídias sociais na empresa - O relacionamento online com o mercado/ 2010

\section{A voz ampliada}

Esta pesquisa, de natureza bibliográfica e exploratória, deriva da dissertação de mestrado "Reclame Aqui Cidades: inovações da mídia social para o exercício da cidadania" (GISOLDI, 2013) e busca entender essas mudanças de atitude dos grupos sociais com a chegada de novas plataformas tecnológicas por diferentes conceitos já empregados por teóricos das escolas da área de humanas.

Para que sejam compreendidos os passos que levam os cidadãos a exporem sua insatisfação via plataformas virtuais é importante remeter ao passado com base em elementos que traduzam a cidadania, antes do universo de plataformas virtuais que existem nos dias de hoje.

Procurando narrar a cidade com base na história, Brites (2013, p. 177) explica que identificam-se os primórdios da cidadania na Grécia clássica, sendo utilizada para se referir aos direitos dos cidadãos que viviam e conviviam na polis. De acordo com a autora, na Roma antiga, a cidadania era também considerada sob o ponto de vista legal: o cidadão protegido pela lei.

As origens da cidadania são visíveis nas disposições legais que atribuem direitos cívicos aos indivíduos, aos cidadãos, e acabam por se estender à política, com a implantação dos estados 
democráticos liberais, nos séculos XVIII e XIX, embora estivesse longe de abranger os indivíduos deforma equitativa (BRITES, 2013, p. 177).

Contudo, Brites (2013, p.178) pondera quenaquela época, esta ideia de cidadania estava ainda confinada a grupos restritos de pessoas. A noção de cidadania foi acolhendo os pressupostos de responsabilidade e de participação cívico-política e incorporando os direitos socioeconômicos, políticos e culturais. $\mathrm{O}$ cidadão conquistou direitos e deveres e começou a ser recolocado no centro de participação e de responsabilização social. Esta responsabilização social, aparentemente universal, não atingiu de forma igualitária todos os cidadãos. Em termos formais, as mulheres só conquistariam o direito de voto séculos mais tarde. Em termos reais, a obtenção da democracia tem sido feita em várias velocidades, apesar de o conceito parecer igualitário.

Ainda segunda a autora, a sociedade política sobrepôs o indivíduo ao coletivo no que respeita aos valores de cidadania, e este novo período vem reforçar o papel interventivo do indivíduo, a sua responsabilidade de participação cívico-política. O individualismo vem servir para ressaltar as diferenças entre as pessoas, contribuindo para um processo de emancipação, com autonomia e bem-estar pessoal, centrado nos projetos pessoais. Numa primeira instância, o individualismo foi, pode-se dizer, positivo, mas acabaria por contribuir para uma certa desorganização social.

Brites (2013) frisa que a cidadania cruzou com o conceito de direitos humanos. Isso, muito em consequência de uma tendência de integração política que não foi acompanhada de uma integração social. As esperanças subjetivas nem sempre acompanham as realidades objetivas. Por isto mesmo os excluídos traduzem o déficit da cidadania.

"O pressuposto de que os 'homens são livres e iguais em direitos', como já assinalado, deixa de fora a noção efetiva de desigualdades. E houve muitas pontas soltas neste processo de interiorização histórica da concepção de cidadania" (BRITES, 2013, p. 178).

O espaço público onde se desenrolam as atividades de cidadania está, por isso, muito longe de ser o ideal e de ser composto por indivíduos que, de uma forma linear, discursam e deliberam.
Historicamente, as mulheres foram alvo de exclusão social e política, sendo impedidas social e legalmente de exercerem plenamente a sua condição de cidadãs. $O$ movimento feminista, fortemente influenciado pela Revolução Francesa e pelas revoluções do século XVIII, no século XX foi reforçado, especialmente na década de 1960 , tentando o feminino conquistar um estatuto de igualdade.

Brites (2013) destaca ainda que a cidadania é, também, enfraquecida pela falta de reconhecimento dos indivíduos e dos grupos em que se inserem algumas minorias como as étnicas e as sexuais, que adquirem maior visibilidade por meio das mídias. Outras minorias começam a revelar-se: os desempregados, os que não têm acesso ou que não sabem usar as tecnologias Web, ou seja, os Web-excluídos.

Partindo, então, do princípio de que os media (como se refere a autora) têm um papel importante nesse processo de aproximação dos jovens às cidadanias, parece-nos, de acordo com Brites (2013, p. 182), que as movimentações que ocorrem no espaço público devem ser entendidas numa perspectiva em que as mídias não são espaços de ruptura entre os velhos e os novos meios de comunicação, mas sim como espaço e meios coexistentes. O autor lembra que "a necessária complementaridade entre os diferentes meios de comunicação permite a existência de um espaço comunicativo que pode ser explorado nas suas mais diversas facetas, contribuindo para o estreitamento de relações em sociedade" (BRITES, 2013, p. 182).

Para Brito (2006, p. 16), “os governos estão se reinventando quando incorporam a rede em seus processos sociais ou político-eleitorais". Da mesma forma, Gisoldi e Pessoni (2013), argumentam com base na explicação de Nicolini e Ribeiro (2004), que afirmam que o e-government atua na prestação de serviços ao cidadão (e-administração), no fomento à extensão dos processos democráticos (e-democracia), na dinamização dos processos internos e de elaboração de políticas públicas (e-governança).

E neste sentido objetiva ampliar as discussões, democratizar o acesso à informação, dinamizar a possibilidade, a realizar negócios e economizar dinheiro dos recursos públicos. Estes autores observam que a maioria dos governos têm empreendido esforços para construir um governo eletrônico "e-gov" (ou governo digital, como um conceito mais amplo), 
tendo como objetivo ações públicas direcionadas ao cidadão; ofertas de meios de acesso a informações e serviços; além da organização das informações dentro dos órgãos do governo, troca de informações entre as várias esferas do governo e suporte a interoperabilidade (GISOLDI e PESSONI, 2013).

Para Nicolini e Ribeiro (2004), as novas tecnologias de informação e comunicação têm o potencial para melhorar a eficiência na prestação de serviços públicos e privados, melhorar a inserção das empresas. Moraes (2000) é enfático ao afirmar em seus estudos que a militância online vem alargar a teia comunicacional planetária, usufruindo de uma das singularidades do ciberespaço: a capacidade de disponibilizar, em qualquer espaço-tempo, variadas atividades, formas e expressões de vida.

Contudo, Moraes (2000) afirma que não se trata de transformar a internet em um celeiro de todas as virtudes. Muito menos de imaginar um Eldorado digital, habilitado a suplantar o poderio de veiculação dos megagrupos - o que seria, além de tolice (segundo o autor), desconhecer o indiscutível predomínio dos conglomerados multimídias no atual cenário de transnacionalização dos mercados de informação e entretenimento.

Em seu texto, Moraes (2000) ressalta a emergência de potencialidades no âmbito virtual, fundadas em práticas comunicacionais interativas, descentralizadas e não submetidas aos mecanismos habituais de seleção e hierarquização adotados pela grande mídia. As entidades civis valem-se da internet enquanto esfera pública de comunicação, livre de regulamentações e controles externos, para veicular informações e análises quase sempre orientadas para o fortalecimento da cidadania e para o questionamento de hegemonias constituídas. Isso significa apontar e valorizar espaços alternativos e promissores de difusão de conteúdos contrahegemônicos, sob inspiração das plataformas reivindicantes de organismos sociais e políticos que se opõem à lógica perversa de reprodução do capital.

Rothberg e Liberato (2013, p. 8) afirmam que a internet pode constituir um meio de oferta de dados necessários para embasar debates cívicos, tornandose recurso importante por possibilitar o engajamento nos assuntos públicos. $\mathrm{O}$ fato de servir ao acesso da informação no tempo, espaço e forma abertos às preferências individuais torna a internet oportuna aos usuários, que podem pesquisar sobre diversos temas de acordo com seu interesse e disponibilidade, manifestar suas perspectivas e construir arenas comunicativas.Dessa forma, destacam que:

A internet é capaz de auxiliar no engajamento político do cidadão a partir da interação que se estabelece entre sociedade civil e representantes políticos. A partir do contato mais próximo, os agentes políticos podem entender as demandas dos cidadãos e promoverem mudanças significativas. Isso provocaria satisfação dos envolvidos atendidos, que passariam a perceber a política como algo próximo, como interesse público, diminuindo o distanciamento entre cidadãos e Estado (ROTHBERG; LIBERATO, 2013, p. 8).

Ainda sobre internet, Rothberg e Liberato (2013, p. 8)destacam que, neste contexto, assumese que a democracia digital possibilita, em primeiro lugar, o fortalecimento da cidadania por meio do aumento da transparência das ações públicas, novas formas de fiscalização e responsabilização dos representantes políticos, além do aumento na participação e engajamento político dos cidadãos por meio de plataformas digitais. Em segundo lugar, assume o papel da representação das minorias e aumento das oportunidades de participação na formulação da decisão política.

A publicação da Organização das Nações Unidas (ONU) E-Government for the People E-GovernmentSurvey de 2012, destaca (p. 44) que apesar da ampla representação regional, a participação eletrônica permanece largamente inexplorada para muitos países. Este conceito, que deriva de uma aceitação da inclusão online dos cidadãos para o desenvolvimento sustentável, prevê a prestação de informação seguida por consulta, gabarito e inclusão de pontos de vista do cidadão na tomada de decisões ativa. Veja a tabela a seguir: 
Tabela 1 - Abertura dos governos para participação online

\begin{tabular}{|c|c|c|c|c|c|}
\hline & Country & $\begin{array}{l}\text { E-infor- } \\
\text { mation }\end{array}$ & $\begin{array}{l}\text { E-consul- } \\
\text { tation }\end{array}$ & $\begin{array}{r}\text { E-decision } \\
\text { making }\end{array}$ & Total \\
\hline \multirow{7}{*}{$\begin{array}{l}\text { Over } \\
67 \%\end{array}$} & Netherlands & 75 & 84 & 67 & 81 \\
\hline & Republic of Korea & 75 & 78 & 100 & 81 \\
\hline & Kazakhstan & 100 & 76 & 67 & 77 \\
\hline & Singapore & 75 & 76 & 83 & 77 \\
\hline & United Kingdom & 100 & 70 & 83 & 74 \\
\hline & United States & 75 & 78 & 50 & 74 \\
\hline & Israel & 75 & 73 & 67 & 72 \\
\hline \multirow{29}{*}{$\begin{array}{r}34 \%- \\
66 \%\end{array}$} & Estonia & 75 & 65 & 33 & 62 \\
\hline & Colombia & 75 & 59 & 50 & 60 \\
\hline & United Arab Emirates & 50 & 54 & 100 & 60 \\
\hline & Egypt & 25 & 54 & 83 & 55 \\
\hline & Bahrain & 50 & 49 & 83 & 53 \\
\hline & Chile & 25 & 59 & 33 & 53 \\
\hline & Russian Federation & 50 & 59 & 17 & 53 \\
\hline & Qatar & 75 & 51 & 33 & 51 \\
\hline & Saudi Arabia & 50 & 49 & 67 & 51 \\
\hline & Mongolia & 75 & 43 & 67 & 49 \\
\hline & France & 50 & 43 & 67 & 47 \\
\hline & Mexico & 25 & 51 & 33 & 47 \\
\hline & Denmark & 25 & 51 & 17 & 45 \\
\hline & El Salvador & 0 & 54 & 17 & 45 \\
\hline & Lithuania & 100 & 38 & 33 & 43 \\
\hline & Brazil & 0 & 43 & 50 & 40 \\
\hline & Brunei Darussalam & 50 & 38 & 33 & 38 \\
\hline & Hungary & 50 & 30 & 67 & 36 \\
\hline & Oman & 50 & 32 & 50 & 36 \\
\hline & Peru & 50 & 35 & 0 & 32 \\
\hline & Rep. of Moldova & 25 & 32 & 33 & 32 \\
\hline & Austria & 50 & 27 & 33 & 30 \\
\hline & Portugal & 50 & 32 & 0 & 30 \\
\hline & Ethiopia & 0 & 32 & 17 & 28 \\
\hline & Greece & 0 & 30 & 33 & 28 \\
\hline & Thailand & 0 & 30 & 17 & 26 \\
\hline & Argentina & 50 & 22 & 17 & 23 \\
\hline & Croatia & 25 & 19 & 50 & 23 \\
\hline & Kyrgyzstan & 0 & 30 & 0 & 23 \\
\hline
\end{tabular}

Fonte: E-Government for the People E-Government Survey de 2012, p 44.
Terossie Leme (2013) apontam que, segundo dados ${ }^{1}$ publicados em 2013, no mundo todo, existem em torno de 2,7 bilhões de usuários da internet, que representam somente $39 \%$ da população total. Obviamente, esse número representa um grande avanço em relação ao pouco mais de $10 \%$ de penetração da tecnologia em 2000, mas não se pode criar expectativas de que o crescimento continue nesse ritmo, já que entre os mais de $60 \%$ restantes da população, a maioria está em países subdesenvolvidos.

A comunicação que concorre para a cidadania esbarra, assim, em um primeiro obstáculo, que é a dificuldade de indivíduos e grupos de lidarem com as diferenças que são "escancaradas" pela Internet. Não somente opiniões, mas as próprias concepções da realidade, sobre direitos e deveres, divergem e nada garante que haverá abertura para a negociação que a cidadania demanda. Pelo contrário, muitas vezes observamos nas redes sociais, por exemplo, pré-julgamentos, trocas de acusações, ofensas e opiniões não explicadas, o que descaracteriza o diálogo (TEROSSI; LEME, 2013, p.8).

Terossi e Leme (2013, p. 10 e 11) afirmam que as interações nas redes sociais que tratam de temas da cidadania são um importante objeto de estudo para a comunicação, uma vez que têm importância na formação da opinião pública sobre temas de interesse da sociedade.

Quando o assunto é cidadania, segundo os autores, para que haja negociação simbólica entre as diferentes demandas da sociedade, é preciso muito mais que um canal de expressão para os cidadãos. A superexposição e o excesso de informações tornam mais visíveis não só o que há de comum, mas, principalmente, as diferenças, o que pode resultar em reações negativas ao outro. Se os indivíduos têm dificuldade em se comunicar com os outros e resistem às informações que os incomoda, quando o assunto é cidadania, as negociações entre as diferentes demandas tornam-se ainda mais complexas.

Também é preciso considerar que a incomunicação é um limite da comunicação e que, por isso, não é porque as redes sociais possibilitam interagir

\footnotetext{
${ }^{1}$ Dados publicados pela União Internacional de Telecomunicações, que é uma agência da Organização das Nações Unidas dedicada a temas relacionados às Tecnologias da Informação e Comunicação. Disponível em: http:// www.itu.int/en/ITU-D/Statistics/Documents/facts/ICTFactsFigures2013. pdf, acesso em setembro. 2013.
} 
com qualquer pessoa, sobre qualquer assunto que haverá entendimento total entre os seus usuários (TEROSSI; LEME, 2013, p.11).

Por fim, não se deve ignorar a exclusão majoritária da população da internet. Tal fenômeno certamente restringe, conforme a visão do autor, a representatividade das vozes que se manifestam nas redes sociais, comprometendo a pluralidade dos diálogos que possam ser estabelecidos (TEROSSI; LEME, 2013, p.11).

O governo e democracia na forma eletrônica valorizam o processo de provisão de informações aos membros da comunidade e dependendo do projeto ou modelo adotados pode gerar a potencialidade para a redistribuição ou concentração do poder político. Na democracia no módulo tecnológico não só os governos podem ser seus agentes, mas também indivíduos e coletivos organizados em sociedade, que passam a estabelecer novas formas de relações de informação e comunicação no território. (MATIAS e SILVA, 2009, p.7)

Especialmente no coletivo, as possibilidades de ser reconhecido, de ser levado em consideração e de contar as decisões dependem da capacidade dos relatos de superar a tensão entre o que é o indivíduo e o que ele pretende ser. Em segundo lugar, as pessoas têm a relação também constitutiva do contar (narrar e ser levado em conta) com o fazer contas, que tem um significado duplo. Pois se, por um lado, instaura a relação entre o reconhecimento e a participação cidadã, a capacidade de participação dos indivíduos e coletividades naquilo que lhes concerne, ao cooptar pelo valor (comercial) o sentido das traduções culturais e da circulação das narrações (MARTINBARBERO, 2010, p.217).

O autor complementa:

Falamos do direto dos cidadãos e dos grupos sociais ao acesso à informação não só como receptores, mas também como produtores; e também ao direito à participação do, e no, conhecimento. Pois, por um lado, a hipervalorização da informação está produzindo uma forte desvalorização dos saberes tradicionais não informatizáveis (MARTINBARBERO, 2010, p.228).

O cidadão neste novo contexto tem à disposição canais construídos nas novas plataformas para expressar seus anseios, indagações e informações que julgar relevante.

\section{O mesmo stakeholder em novas plataformas}

A reflexão de vários autores faz entender sobre a importância de estar atento ao novo comportamento do cidadão perante as novas plataformas de comunicação. No entanto, é bom entender que as reclamações referentes ao mau-atendimento ou outros problemas crônicos ocorriam no passado, mas foram amplificadas com o advento das novas tecnologias.

Recuero (2009, p.25) atribui às redes sociais o poder de amplificar a voz das pessoas, mais construção de valores e maior potencial em espalhar informações.

A internet permite estabelecer plataformas de diálogo para que as pessoasinterajam localmente ou transcendam as fronteiras do Estado-nação, numa rede anárquica de interações. Possibilita que muitos indivíduos se engajem em listas de grupo, chats rooms, fóruns da web, fazendo avançar conversações sobre todo tipo concebível de questões (MAIA, 2008, p. 117).

Outro que ressalta a importância da tecnologia em relação ao comportamento do ser humano é Josgrilberg:

Uma tecnologia incorporada por uma sociedade altera as relações sociais, a percepção do espaço, do tempo, ou seja, modifica a relação do ser humano com a natureza e entre os próprios seres humanos. Não importa se para melhor ou pior, há uma mudança na relação com o mundo e na compreensão que se tem dele. Argumentar que o computador, o telefone, a faca ou qualquer outro instrumento sozinho não altera a organização do espaço pode ser uma posição enganosa. A tecnologia só tem significado em seu uso dentro de relações sociais dadas. Logo, a tecnologia necessariamente está para alguém. Vista dessa forma, ela não é neutra (JOSGRILBERG, 2008, p. 281).

Ganhar voz na internet não depende necessariamente de privilégios financeiros, raciais ou geográficos, mas relaciona-se com a aquisição de capacidade discursiva. Tais espaços virtuais podem ajudar os indivíduos que sofrem de injustiça distributiva ou de exclusão simbólica a examinar criticamente os próprios valores e a interpretar a própria situação em relação aos outros atores sociais, bem como construir novos padrões de 
autoapresentação e reconhecimento (ALEXANDER, 1997, p. 25; HABERMAS, 1997).

No caso das administrações públicas, criar ferramentas de SAC virtual para atender às demandas dos munícipes e monitoramento de imagem é uma forma de agilizar o serviço e medir a percepção do munícipe quanto à qualidade dos serviços públicos.

De acordo com Galindo (2011, p. 15),

[...] é possível perceber que as mudanças em curso estão dotando os consumidores de uma força ou capacidade expressiva que no nível individual se caracteriza como um micropoder, no sentido coletivo se firma como uma revolução, ou um contra fluxo nas relações com as organizações e instituições desprovidas de sensibilidade para entender o consumidor contemporâneo com mobilidade e espaço na ágora virtual.

Opinião semelhante expressa Roman:

As vozes inteligentes dos "loucos", as vozes criativas dos imprestáveis, as vozes engenhosas dos "inúteis", às quais a empresa esteve surda, estão fazendo falta. Já se faz hora da incorporação produtiva dessa polifonia nos projetos organizacionais (ROMAN, 2005, p. 82).

Esse autor ainda destaca que os conteúdos trabalhados junto ao consumidor-cidadão, mesmo aqueles oriundos do marketing, da publicidade, do governo, da mídia ou das comunidades-tribos, apontam para um lugar comum: "Um discurso verdadeiro, coerente, transparente e essencialmente de duas mãos, afinal, eles têm vozes e estão em busca de relacionamentos simétricos" (GALINDO, 2011, p.15).

[...] o neoconsumidor vem migrando das mídias tradicionais, como jornais, revistas e televisão, para as novas plataformas digitais, como internete celular, consideradas até recentemente como um mercado de nicho. Plataformas digitais que hoje são primordiais no dia a dia de milhões de pessoas no Brasil e no mundo. [...] o neoconsumidor realiza pesquisas e busca informações sobre produtos, serviços e novidades. Algo totalmente novo para quem há 10 anos buscava novidades em revistas, jornais e televisão (SOUZA, 2009, p. 234).

Souza (2009, p.233) destaca que, para ter acesso às informações e novidades, o neoconsumidor vai às plataformas digitaisonde há uma geração colaborativa de conteúdo, que se tornou importante moeda social, com o valor - ainda não calculado, mas efetivo - do compartilhamento de experiências de compra e utilização de produtos e serviços, difundidos livremente entre as diversas comunidades e usuários de Internet no mundo. Isso tem profundo impacto sobre os negócios das empresas, que passam a ser pressionadas a oferecer melhores preços e serviços, reduzem suas margens e têm mais necessidade de se diferenciar.

No que tange ao cidadão, que é o objeto deste estudo, Haswani (2006, p.38) considera que a consciência cidadã, a qual a sociedade vem adquirindo em relação ao estado, seu papel e suas obrigações, torna os indivíduos em agentes transformadores, porque é capaz de cobrar, denunciar ou, simplesmente, solicitar aos órgãos estatais informações precisas sobre assuntos de seu interesse.

Brito (2006, p.121) atribui a crescente transformação da clássica democracia representativa para os moldes da democracia eletrônica à revolução tecnológica, por meio da qual a comunicação é dupla-mão, mas transparente e interativa.

Segundo Domingues (2010, p. 65), a possibilidade de interagir com os meios digitais, criar conteúdos e distribuí-los em escala mundial, por meio da rede, possibilitou o surgimento de novos comportamentos dos cidadãos, que estão, como nunca, no controle das suas relações midiáticas. Já Mounier enfatiza seu conceito destacando o impacto desse personagem social:

Os netizens utilizam a internet como forma de ampliar debates e trazer à luz questões que, muitas vezes, não dispõem de um espaço para serem debatidas na mídia de massa. Entretanto, para que esses questionamentos ganhem força junto ao grande público, não raro é necessário que os assuntos debatidos surjam nas mídias digitais e depois sejam levados para o mundo off-line a despeito de não ganharem força frente à opinião pública (MOUNIER, 2006, p.191).

Em português, este conceito híbrido de netizen, embora interessante no seu conteúdo, é de difícil tradução. Derivando de "rede" e de "cidadãos", obtemos qualquer coisa como "redadãos", o que não apresenta uma sonoridade das mais harmoniosas (ANDRADE, 2007, p. 3).

Para Kunsch (2007, p.44), muitos autores já escreveram sobre públicos em relações públicas. 
Mas, numa visão contemporânea, é preciso considerar as tipologias dos públicos dentro da dinâmica da história, levando em consideração as forças sociais do macro-ambiente e os comportamentos dos grupos de interesses que podem vir a formar um novo público. "Um público que praticamente nunca foi pensado como prioritário ou que não tem nenhum vínculo com a organização, dependendo dos acontecimentos, isto é, de como o comportamento institucional o afeta, pode vir a ser um público estratégico."

Mencione-se, a propósito, o conceito de stakeholders, que hoje muitos simplesmente usam no lugar de "públicos". Mas ele só não pode ser usado para qualquer tipo de públicos. Diríamos que ele se refere somente a públicos "realmente estratégicos". No livro Relações públicas e modernidade (Kunsch, 1997, p. 119), mostramos "a diferença que Hunt e Grunig fazem entre "público" (genericamente) e stakeholders (uma espécie de acionistas, sem o serem de forma financeira). Para eles, a distinção é sutil, mas ajuda a entender o planejamento estratégico de relações públicas. Stakeholders são pessoas ou grupos que estão lincadas (linked, mais do que apenas ligados) a uma organização porque entre as duas partes há interesses recíprocos. Quem tem um link com uma organização tem um stake com ela, faz uma aposta nela, o que se pode entender como uma quota nela aplicada. Um stakeholder, portanto, é "qualquer indivíduo ou grupo que pode afetar a organização ou é afetado por suas ações, decisões, políticas, práticas ou resultados", resumem Hunt e Grunig, citando Archie B. Carrol. Enfim, trata-se, para nós, dos públicos-alvos ou, numa linguagem mais moderna, "públicos estratégicos". E, ainda com base em Grunig e Hunt (1994), acrescentávamos (Kunsch, 1997, p. 120). (KUNSCH, 2007, p.45).

Para a autora, o primeiro passo, no gerenciamento estratégico de relações públicas, está em mapear os públicos que estão vinculados a uma organização. Nessa lista típica acabarão sendo arrolados: proprietários, advogados do consumidor, clientes, concorrentes, meios de comunicação, empregados, grupos de interesse especial, ambientalistas, fornecedores, governos e organizações da comunidade local. Uma comunicação permanente com esses públicos estratégicos ajuda a construir um relacionamento estável e de longo prazo, que facilitará a administração de conflitos que possam ocorrer (KUNSCH, 2007 , p.45).
$\mathrm{Na}$ era digital o conceito tradicional de públicos dimensionados por espaço geográfico, nas categorias de interno, misto e externo não consegue acompanhar a dinâmica dos dias de hoje. Os públicos se formam dependendo de como são afetados pelas instituições e organizações. Com a internet, a formação de públicos virtuais é uma constante e incontrolável. Nesse contexto vale como recorte discorrer sobre as comunidades virtuais e as redes sociais como um público fundamental, que não pode ser ignorado pelos setores de comunicação das organizações.

Kunsch (2007) cita Gilles Deleuze e Felix Guattari, no livro "Mil platôs: capitalismo e esquizofrenia" (1995), que se apropriam do paradigma do rizoma (elemento da botânica) para nomear a "sociedade rizomática", que atua como uma rede descentralizada, desterritorializada e como uma forma democrática e construtiva das relações sociais, sem se prender às hierarquias e as convenções tradicionais da visão de sociedade e comunidade.

As ações comunicativas de uma empresa, por exemplo, direcionadas para atingir a sociedade ou mesmo uma comunidade precisam considerar novos fundamentos e conceitos. Entender sociedade como uma população que habita determinado território, cumprindo leis e normas, se articulando em torno de direitos e deveres etc. é uma visão limitada para compreender a complexidade da atual sociedade global. (KUNSCH, 2007, p. 45)

Rosa e Kamimura (2012, p. 16) também observam que ambos os setores das organizações privadas e públicas estão utilizando fortemente os recursos das mídias sociais para atingir seus respectivos objetivos. No entanto, ponderam que as empresas privadas, apesar de entenderem o potencial que trazem as mídias sociais, demonstram que tratam com pouca importância o seu uso e realizam baixos investimentos anuais nas mesmas. "A nova gestão pública empreendedora utilizada nas últimas décadas no Brasil tem favorecido o uso de novas tecnologias da informação como a internet e as mídias sociais para os processos públicos e de campanhas eleitorais".

Os autores detalham que:

O uso das mídias sociais nos Estados Unidos são fortemente utilizados durante as campanhas eleitorais, pode-se analisar que os jovens norte-americanos são aqueles que mais estão envolvidos nas questões cívicas nas redes sociais. Outra questão é 
que mesmo tendo pouca importância nas atividades políticas ou não afetando as opiniões e envolvimento dos eleitores dentro das redes sociais, o fato é que os políticos entendem que este canal de comunicação deve ser ocupado e estão sendo constantemente usados nas eleições. O uso das mídias sociais no Brasil também aparece nas eleições de candidatos,no entanto, alguns especialistas estão vendo o uso das mídias sociais com certo amadorismo, o que ao invés de ajudar na imagem e nas propostas de governo dos candidatos acaba prejudicando-os caso não seja feito de maneira profissional (ROSA; KAMIMURA, 2012, p. 16).

Na visão de Santos, Carniello e Araújo (2013. p.171) a comunicação da administração municipal é uma característica intimamente conectada à democracia e, em um contexto comunicacional baseado na linguagem digital organizada em uma rede de alcance mundial, multiplica suas potencialidades de conexão com os munícipes. Essa afirmação decorre do pressuposto de que a administração municipal dedicada ao desenvolvimento local sustentável, que incorpora os princípios da promoção da equidade social e do uso não predatório dos recursos naturais e econômicos, busca ampliar significativamente os canais de comunicação entre os gestores e a população, contribuindo para a ampliação e a consolidação da democracia participativa.

Porém, segundo os autores, a simples aplicação das ferramentas de comunicação na gestão pública não assegura a ampliação da participação popular na administração municipal, a aplicação mais equitativa dos recursos em benefício da coletividade ou a atração de investimentos aptos a impulsionar o desenvolvimento local. Observa-se que a utilização da comunicação por parte dos gestores municipais deve pautar-se nos pressupostos legais previstos em lei, de modo a possibilitar a nova urbanidade formada pela revisão paradigmática da gestão urbana.

Santos, Carniello e Araújo (2013. p.173) avaliam que a articulação dos atores sociais em redes é relativa aos meios disponíveis de comunicação que pautam os processos formativos e reprodutores das relações sociais. Deste modo, a efetivação de um modelo de gestão capaz de priorizar a participação de atores sociais de todos os setores da sociedade decorre da competência em tornar mídias digitais instrumentos de superação da histórica barreira que segrega amplos setores da população do exercício do poder.

Com o número de pessoas que utilizam as redes sociais virtuais aumentando a cada dia - de acordo com pesquisa da consultoria ComScore - o Brasil é o $4^{\circ}$ país e o que mais cresce em número de usuários no Facebook, com 36 milhões, assim, a tendência dos munícipes optarem por esse tipo de contato com as administrações públicas tende a aumentar nos próximos anos. Portanto, é hora das organizações públicas e privadas se atentarem a nova realidade de participação dos internautas, que derrubam e constroem reputações em um único instante.

\section{Referências}

ANDRADE. Pedro. Corpo virtual e Web 2.0: escritas do feminino na Internet e na blogosfera. Revista do Centro de Estudos de Comunicação e Linguagens da Faculdade de CiênciasSociais e Humanas da Universidade de Lisboa) Lisboa: $n^{\circ} 7$ (2007). Disponível em:> http://www.cecl.com. pt/workingpapers/files/ed7_corpo_virtual_web2.pdf <. Acesso em: 10 out. 2013.

BRITES, Maria José. Os jovens e a cidadania: a relevância do espaço mediático. Caleidoscópio - Revista de Comunicação e Cultura, Portugal, n. 10, p. 177-188, 2011.

BRITO, José Augusto Pereira.Cibercidadania: a virtualização na Comunicação Pública contemporânea. Disponível em: <Http://www.eca.usp.br/departam/crp/ cursos/posgrad/gestcorp/organicom/re_vista4/106.pdf $>$. Acesso em: 20 set. 2013.

CASTELLS, M. A galáxia da Internet: reflexões sobre a Internet, os negócios e a sociedade. Rio de Janeiro: Jorge Zahar, 2003.

DA SILVA MATIAS, Vandeir Robson; COSTA, Bruno Rocha Cordeiro. Internet e política aplicada à gestão urbana no Brasil. Anais: Encontros Nacionais da ANPUR, v. 13, 2013.

DOMINGUES, Ivo. Qualidade nos serviços públicos constrangimentos e possibilidades. Revista Episteme, Lisboa: Universidade Técnica, $\mathrm{n}^{\circ}$ 13-14 (2004): 225242; Disponível em: <http://repositorium.sdum.uminho. pt/bitstream/1 822/6382/4/Qualidade\%20nos\%20 servi\%C3\%A 7os \% 20p\%C3\%B Ablicos\%20-\%20 possibilidades $\% 20 \mathrm{e} \% 20$ bloqueios.pdf $>$. Acesso em 10 out. 2013.

DUARTE, Jorge. Comunicação Púbica. São Paulo: Atlas, 2007. Disponível em: $<$ http://www.jforni.jor.br/forni/files/ ComP\%C3\%BAblicaJDuartevf.pdf $>$. Acesso em: 15 jul. 2013. 
GALINDO, Daniel; BASSETTO, Jefferson. As muitas vozes do consumidor contemporâneo ecoam na ágora virtual. Recife: Intercom, 2011. Disponível em: <http:// www.danielgalindo.ppg.br/As\%20muitas\%20vozes $\% 20$ do $\% 20$ consumidor $\% 20$ contemporaneo $\% 20$ ecoam $\% 20$ na\%20agora\%20virtual.pdf $>$. Acesso em: 14 set. 2013.

GERZSON, Vera Regina Serezer; MÜLLER, Karla Maria. Procac/Canoas: comunicação pública e relacionamento com o cidadão. Revista FAMECOS: mídia, cultura e tecnologia. Porto Alegre, v. 1, n. 38, abr. 2009. Disponível em: <http://revistaseletronicas.pucrs.br/ ojs/index.php/ revistafamecos/article/view/5302/3872>. Acesso em: 10 out. 2013.

GISOLDI, Robson Luiz. Reclame Aqui Cidades: inovações da mídia social para o exercício da cidadania. 2014, São Caetano do Sul. Disponível em: $<$ http://repositorio.uscs.edu. br/handle/123456789/349>. Acesso em fev. 2015.

GISOLDI, Robson Luiz; PESSONI, Arquimedes. O neomunícipe na comunicação pública das cidades do Grande ABC. Parágrafo: Revista Científica de Comunicação Social da FIAM-FAAM, v. 1, n. 1, p. 19-30, 2013. Disponível em: $<$ http://www.revistaseletronicas.fiamfaam.br/index.php/ recicofi/article/view/113>. Acesso em fev. 2015.

HASWANI, Mariangela Furlan. Comunicação Governamental: em busca de um alicerce teórico para a realidade brasileira. Organicom. São Paulo, 2006 (p. 25 39). Disponível em: <http://www.revistaorganicom.org.br/ sistema/intex/php/organicom/article/view/53/187>. Acesso em: 12 out. 2013.

HABERMAS, Jürgen. Mudança estrutural da esfera pública. Trad. Flávio R. Kothe. Rio de Janeiro: Tempo Brasileiro, 1984.

JOSGRILBERG, F. Tecnologia e sociedade: entre os paradoxos e os sentidos possíveis. Comunicação \& Educação, Brasil, v. 10, n. 3, 2008. Disponível em: <http:// revistas.univerciencia.org/index.php/comeduc/article/ view/5154/4782. > Acesso em: 04 mai. 2013.

KUNSCH, Margarida M. Comunicação organizacional na era digital: contextos, percursos e possibilidades. Signo y Pensamiento, n. 51, p. 38-51, 2007.

MAIA, Rousiley CM. Redes cívicas e internet: efeitos democráticos do associativismo. Aurora. Revista de Arte, Mídia e Política. ISSN 1982-6672, n. 2, p. 110-134, 2008. Disponível em: <http://revistas.pucsp.br/index.php/aurora/ article/view/6363>. Acesso em: 10 out. 2013.

MARTIN-BARBERO, Jesús. Convergência digital e diversidade cultural. In: MORAES, Dênis de (org). Mutações do visível. Da comunicação de massa à comunicação em rede. Rio de Janeiro: Pão e Rosas, 2010 (p. 211-235).

MATOS, Heloiza. Comunicação pública, democracia e cidadania: o caso do Legislativo. Líbero: revista do
Programa de Pós-Graduação da Faculdade Cásper Líbero, São Paulo, v. 2, n. 3-4, p. 32-37, 1999. Disponível em: < http://www.teresapitombo.pro.br/documentos/ rpgov0599690.pdf>. Acesso em 07 set. 2013.

MORAES, Dênis de. Comunicação virtual e cidadania: movimentos sociais e políticos na Internet. Revista Brasileira de Ciências da Comunicação, v. 23, n. 2, jul./ dez. 2000.

MOUNIER, Pierre. Os donos da rede. As tramas políticas da Internet. São Paulo: Edições Loyola, 2006.

NICOLINI, A.T.; RIBEIRO, E. B. Q. A sociedade da informação e o e-gov. Florianópolis, 2004. Disponível em: $\quad<$ http://www.slidefinder.net/conceitogov_ govdefinidouso/32350529>. Acesso em: 01 set. 2013.

ONU. E-Government for the People E-Government Survey.2012. Disponível em: <http://www.unpan.org/ dpadm/egovernment/unegovernmentsurveys/tabid/600/ language/en-us/default.aspx> $>$. Acesso em: 11 out. 2013.

RAMINELLI, Francieli Puntel; CHRISTO, Tatiana Vielmo de; FELTRIN, Lohana. OLIVEIRA, Rafael Santos de. Reclame Aqui e Portal da Agência Nacional de Telecomunicações: uma Análise dos Espaços do Ciberconsumidor na Internet. In: SIMPÓSIO DE ENSINO, PESQUISA E EXTENSÃO, 15., 2011, Santa Maria. Anais Eletrônicos... Santa Maria: UNIFRA, 2011. Disponível em: $<$ http://www.unifra.br/eventos/sepe2011/Trabalhos/sociais Aplicadas/Completo/2404.pdf>. Acesso em: 13 out. 2013.

RECUERO, R. Rede Social, in SPYTER, Juliano (Org). Para Entender a Internet - Noções, práticas e desafios da comunicação em rede. E-livro:Nãozero, 2009. Disponível em: <http://www.next.icict.fiocruz.br/arquivos/ Para+entender+a+Internet.pdf $>$. Acesso em: 12 out. 2013.

ROMAN, Artur. O e-mail nas organizações: reconstrução da sociabilidade perdida. Disponível em: $<$ http://www.eca. usp.br/departam/crp/cursos/posgrad/gestcorp/organicom/re vista3/68.pdf >. Acesso em: 01 set. 2013.

ROTHBERG, Danilo; LIBERATO, Fabíola de Paula. Opinião pública e cidadania: a qualidade da informação nos portais eletrônicos de governo das regiões administrativas do Estado de São Paulo. In: CONGRESSO DA COMPOLÍTICA, 5., 2013, Curitiba. Anais Eletrônicos... Curitiba: ABPCP, 2013. Disponível em: <http://www. compolitica. org/home/wp-content/uploads/2013/05/GT01-Comunica\%C3\%A7\%C3\%A3o-e-Democracia -DaniloRothberg.pdf>. Acesso em: 01 set. 2013.

SANTOS, Moacir José dos; CARNIELlO, Monica Franchi; ARAÚJO, Edson Aparecida de Oliveira Querido. Comunicação digital na gestão pública dos municípios da RMVP: acesso à informação, transparência e mecanismos de participação. Revista Brasileira de Desenvolvimento Regional, v. 1 n. 1, p. 167-184, outono de 2013. Disponível 
em: $\quad<\quad$ http://proxy.furb.br/ojs/index.php/rbdr/article/ view/3654/2265>. Acesso em: 10 out. 2013.

SOUZA, Marcos Gouvêa de. Neoconsumidor - Digital, Multicanal e Global. São Paulo: GS\&MD Editores, 2009.

TEROSSI, Karen; LEME, Camila Alves Ribeiro Paes. Qual comunicação? Uma reflexão sobre cidadania e novas tecnologias.Intercom - Sociedade Brasileira de Estudos Interdisciplinares da Comunicação. 2013 Disponível em: <http://portalintercom.org.br/anais/centrooeste2013/ resumos/R36-0616-1.pdf>. Acesso em: fev. 2015.

UNIES, Nations. United Nations e-government survey 2008: From e-government to connected governance.UN, 2008. Disponível em: <http://www.unpan.org/egovkb/global_ reports/08report.htm>. Acesso em 01 out. 2013.

WEBER, Maria Helena. Na comunicação pública, a captura do voto ${ }^{1}$. Logos 27: Mídia e Democracia, ano 14, 2007. Disponível em: <http://www.logos.uerj.br/PDFS/27/03 MARIA_WEBER.pdf $>$.Acesso em: 01 out. 2013

Recebido em: 14/11/2014

Aceito em: 29-04-2015 